\title{
Metode Erroneous Example (Contoh Yang Keliru) Pada Pembelajaran Matematika di Perguruan Tinggi
}

\author{
Nur Baiti Nasution a,1,* Dewi Mardhiyana ${ }^{\mathrm{b}, 2}$ \\ a,b Pendidikan Matematika Universitas Pekalongan, Jl. Sriwijaya No. 3, Pekalongan, Jawa Tengah, Indonesia \\ 1 nurbaiti.nasution@unikal.ac.id*, ${ }^{2}$ dewimardhiyana139@gmail.com \\ * Corresponding Author
}

Diterima 19 Maret 2021; Disetujui 20 Maret 2021; Diterbitkan 20 Maret 2021

\begin{abstract}
Students errors are actually provide resources for teaching. Using students error, lecturer can emphasized certain concept while teaching, especially those concepts which make students confused. One of the teaching method that use students error is erroneous example. In this article, we developed a certain task using erroenous example method. The task consists of 10 question. Each question is made to tackle students understanding about a concept that is often mistaken by students. For each question, we give a correct/incorrect worked example, then students are asked to find the mistakes (if it is incorrect) or justify the steps (if it is correct). This study is a descriptive qualitative study that aims to describe the task and students response after doing the task. The method of collecting data was using observation, documentation, and interview. The results shows us that erroneous example task can be categorized difficult for students. However, it is also proved that it can be used to supporting students mathematics communication.
\end{abstract}

KEYWORDS

Erroneous example Diferential equations Student's Error

This is an openaccess article under the CC-BY-SA license

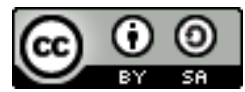

\section{Pendahuluan}

Selama ini telah banyak penelitian yang menganalisis kesalahan siswa dalam pengerjaan soal-soal matematika (Abdullah et al., 2015; Ang \& Shahrill, 2014; Mctavish \& Larusson, 2014; Nasution, 2018; Yee Ming et al., n.d.). Akan tetapi, kesalahan-kesalahan pengerjaan siswa tersebut belum dieksplorasi lebih lanjut untuk meningkatkan hasil belajar matematika siswa. Masih banyak hasil analisis kesalahan yang belum digunakan dalam pembelajaran di sekolah. Hal ini dikarenakan, sejauh ini, belum banyak metode pembelajaran yang memanfaatkan kesalahan siswa dalam mengerjakan soal matematika di dalam kelas. Hal ini cukup disayangkan karena secara umum, siswa dari tahun ke tahun melakukan kesalahan yang sama dalam pengerjaan soal matematika. Untuk itu, diperlukan metode pembelajaran yang menggunakan kesalahan pengerjaan siswa sebagai dasar pembelajaran. Salah satu contoh metode tersebut adalah metode erronneous example (contoh yang keliru).

Tsovaltzi, dkk, menjelaskan bahwa erroneous example adalah contoh soal yang telah dikerjakan yang memuat satu atau dua kesalahan yang mana siswa diminta untuk mencari kesalahan pengerjaan tersebut (Tsovaltzi et al., 2009, 2010). Secara sekilas, metode ini mirip dengan penberian contoh yang telah dikerjakan (worked example) yang telah umum diberikan dalam setiap buku pegangan matematika. Akan tetapi, metode contoh yang keliru tidak hanya menekankan agar siswa memahami konsep seperti halnya worked example (Kay \& Edwards, 2012; McGinn et al., 2015; van Loon-Hillen et al., 2012), tetapi penggunaan contoh yang keliru mnekankan agar siswa lebih memahami logika dan alasan dibalik setiap pengerjaan soal terlebih dalam mata pelajaran matematika (Jaeger et al., 2020; McLaren et al., 2016; Melis, 2004; Tsovaltzi et al., 2009).

Melihat fakta-fakta tersebut, tampaknya menggunakan metode contoh yang keliru dalam pembelajaran matematika merupakan salah satu langkah yang menjanjikan. Akan tetapi, di Indonesia sendiri masih jarang penelitian/pembelajaran matematika yang menggunakan metode tersebut. Terlebih lagi di perguruan tinggi. Salah satu hal yang menjadi kendala adalah bahwa untuk menggunakan metode tersebut, guru harus menempuh langkah panjang hanya untuk persiapan sebelum mengajar. Langkah-langkah yang harus dilakukan tersebut adalah 1) meneliti terlebih dahulu 
tipe-tipe kesalahan yang sering dilakukan oleh siswa dalam materi yang akan diajarkan, 2) membuat bahan ajar menggunakan tipe-tipe kesalahan yang dilakukan siswa tersebut, dan 3) mengajar menggunakan bahan ajar tersebut. Bahan ajar yang dibuat dapat berupa LKS atau modul berisikan materi biasa. Karakteristik yang harus ada pada bahan ajar yang dibuat adalah bahwa harus ada contoh soal yang sengaja dibuat keliru untuk dikerjakan oleh siswa.

Pada soal tersebut, siswa diberikan situasi dimana soal telah dikerjakan tetapi memuat kesalahan. Selanjutnya, tugas siswa adalah mencari kesalahan tersebut dan memberikan jawaban yang benar (Melis, 2004, 2005). Tidak hanya contoh yang keliru, pada beberapa versi bahan ajar yang menggunakan metode contoh keliru, diberikan juga soal yang telah dikerjakan dengan benar dan siswa diminta untuk memberikan alasan mengapa langkah-langkah tertentu pada soal tersebut benar (Lange et al., 2014). Oleh sebab itu, karaktertistik lain bahan ajar dengan contoh yang keliru adalah harus menjelaskan apakah contoh ini keliru atau tidak, sehingga siswa tidak bingung. Untuk membuat soalsoal tersebut tidaklah mudah dan memerlukan waktu yang relative lama.

Penelitian di Indonesia yang telah menggunakan metode contoh yang keliru baru sebatas mendesain konsep e-learning menggunakan metode tersebut menggunakan LMS Moodle (Nasution \& Mardhiyana, 2019). Penelitian tersebut belum membahas mengenai 1) bagaimana model soal menggunakan metode contoh yang keliru dalam pembelajaran matematika di perguruan tinggi yang mana didominasi dengan soal uraian/essay dan 2) bagaimana tanggapan mahasiswa mengenai bahan ajar yang mengimplementasikan metode tersebut. Kedua pertanyaan penelitian itulah yang dijawab pada artikel ini.

\section{Metode}

Penelitian ini dilaksanakan pada Program Studi Pendidikan Matematika Universitas Pekalongan. Subyek penelitian ini adalah mahasiswa semester V Program Studi Pendidikan Matematika Universitas Pekalongan Tahun Akademik 2018/2019 khususnya yang mengikuti mata kuliah Persamaan Diferensial. Langkah penelitiannya yang dilakukan adalah sebagai berikut. Langkah Pertama adalah mengembangkan seperangkat tugas untuk mata kuliah Persamaan Diferensial yang berisi 10 permasalahan. Masing-masing permasalahan sudah memiliki jawaban. Akan tetapi, pada jawaban tersebut ada jawaban yang benar dan ada jawaban yang salah. Untuk jawaban yang salah, mahasiswa diminta untuk mencari letak kesalahannya, alasan mengapa hal tersebut salah, dan bagaimana jawaban yang benar. Sedangkan untuk jawaban yang benar, mahasiswa diminta untuk memberikan justifikasi mengenai jawaban tersebut. Desain ini mengikuti rancangan dari beberapa penelitian yang telah mendesain bahan ajar menggunakan contoh yang keliru sebelumnya (Lange et al., 2014; Melis, 2004).

Kajian mengenai kesalahan yang sering dilakukan oleh mahasiswa pada materi yang akan digunakan sebagai obyek pembelajaran dirasa perlu dilakukan untuk menjawab pertanyaan penelitian yang pertama yaitu bagaimana model soal menggunakan metode contoh yang keliru dalam pembelajaran matematika di perguruan tinggi yang mana didominasi dengan soal uraian/essay. Pada penelitian kali ini, metode pengumpulan data yang digunakan adalah metode dokumentasi. Metode dokumentasi ini dilakukan untuk mengumpulkan hasil kerja mahasiswa terdahulu dan juga observasi terhadap subyek penelitian. Metode pengumpulan data berikutnya adalah metode observasi. Observasi dilakukan sebelum jalannya penelitian, dengan demikian, mata kuliah yang sesuai untuk dijadikan sarana observasi adalah mata kuliah yang menjadi prasyarat mata kuliah Persamaan Diferensial yaitu mata kuliah Kalkulus Lanjut. Selain dokumentasi dan observasi, jika terdapat kesalahan, juga dilakukan studi pustaka dengan mencari literatur atau hasil penelitian yang membahas mengenai jenisjenis kesalahan yang sering dilakukan pada mata kuliah Persamaan Diferensial.

Setelah rancangan tugas selesai disusun, selanjutnya mahasiswa diminta untuk mengerjakan tugas tersebut di rumah. Hal ini dimaksudkan agar mahasiswa tidak terburu-buru dalam mengerjakan dan menggunakan waktu sebanyak yang mereka perlukan. Melalui langkah ini diharapkan mahasiswa dapat memahami maksud dan kehendak soal secara menyeluruh dan tidak asal mengerjakan. Adapun waktu yang diberikan untuk mengerjakan soal tersebut adalah 2 minggu. Waktu yang diberikan kepada mahasiswa cukup lama karena jumlah soal yang diberikan juga cukup banyak. Setelah periode 
pengerjaan tugas telah berakhir, mahasiswa diminta mengumpulkan tugas, kemudian dosen mengonfirmasi jawaban soal tersebut.

Langkah berikutnya, untuk menjawab pertanyaan penelitian kedua yaitu bagaimana tanggapan mahasiswa mengenai bahan ajar yang mengimplementasikan metode tersebut, 2 orang peserta kuliah diwawancara untuk ditanyai pendapatnya mengenai tugas yang telah diberikan. Wawancara dilakukan secara tidak terstruktur dan kemudian hasil dianalisis secara kualitatif. Sebelum dilakukan wawancara, hasil pekerjaan mahasiswa dianalisis terlebih dahulu dan dibuat beberapa dugaan. Pada penelitian ini, wawancara berfungsi sebagai sarana untuk konfirmasi terhadap dugaan yang telah disusun sebelumnya.

\section{Hasil dan Pembahasan}

\subsection{Rancangan Tugas dengan Metode Erroneous Example}

Untuk membuat rancangan tugas yang memuat contoh yang keliru, terlebih dahulu dikumpulkan data-data mengenai kesalahan yang sering muncul kemudian dibuat soal yang memuat contoh keliru terkait kesalahan-kesalahan tersebut. Hal ini dilakukan dengan melihat dokumentasi hasil pekerjaan mahasiswa sebelumnya. Selain itu, data juga dikumpulkan melalui dan juga dapat menggunakan hasil wawancara atau pengalaman dosen pengampu.

Berdasarkan hasil analisis kesalahan, diketahui bahwa ada 3 jenis/tipe kesalahan. Tipe pertama adalah kesalahan dalam menginterpretasikan pernyataan dalam soal. Salah satu contoh kesalahan dalam tipe ini adalah jika mahasiswa tidak memahami apa yang diketahui atau yang ditanyakan oleh soal. Sebagai contoh, misalkan pada soal meminta solusi khusus dengan nilai awal y (a) $=b$, tetapi mahasiswa banyak yang tidak memahami makna dari notasi tersebut. Tipe kedua adalah kesalahan dalam menghitung atau mengeksekusi suatu aturan, dapat berupa aturan pencarian turunan atau yang lainnya. Adapun, tipe yang ketiga adalah kesalahan dalam langkah membuktikan suatu persamaan. Biasanya mahasiswa salah dalam membuktikan suatu persamaan karena sejak awal kedua ruas sudah ditulis sama, padahal seharusnya ruas kiri terlebih dahulu diuraikan sehingga membentuk ruas kanan.

Untuk setiap soal, dibuatkan suatu masalah yang akan menjadi konteks atau latar belakang dari kasus-kasus kecil. Masalah tersebut umumnya berupa soal cerita mengenai beberapa tokoh yang sedang mengikuti perkuliahan persamaan diferensial dan sedang mengerjakan soal tertentu. Memberikan konteks untuk mewadahi semua kasus ini sesuai dengan yang dilakukan Erica Melis dalam pengembangan contoh soal yang sama (Melis, 2004, 2005). Contoh konteks yang diberikan dapat dilihat pada Gambar 1.

Jawablah pertanyaan-pertanyaan berikut di tempat yang tersedia!

1. Dalam suatu kelas Persamaan Diferensial, Joko, Andi, dan Cica mengerjakan masalah berikut.

Masalah 1. Suatu studi menyatakan bahwa sejak tahun 2010, pertumbuhan jumlah penduduk di suatu daerah adalah 0.02 kali jumlah penduduknya. Jika $P(t)$ menyatakan jumlah penduduk di tahun ke-t dan jumlah penduduk di tahun 2010 adalah 100.000 jiwa.

a. Buatlah model matematika dari permasalahan di atas!

b. Tunjukkan bahwa fungsi $P(t)=A e^{0.02 t}$ merupakan solusi umum model tersebut!

c. Tentukan jumlah penduduk di daerah tersebut pada tahun 2017!

Selanjutnya, jawablah pertanyaan yang berkaitan dengan jawaban masing-masing!

Gambar 1 Contoh Konteks yang Diberikan

Terdapat 2 jenis contoh soal yang dibuat yaitu contoh soal yang memuat pekerjaan benar dan contoh soal yang memuat pekerjaan salah. Pada contoh soal yang memuat pekerjaan benar, mahasiswa diminta untuk memberikan alasan mengapa pekerjaan tersebut benar. Selain itu, mahasiswa juga 
diminta untuk memberikan justifikasi pada langkah yang diberikan. Contoh soal yang memuat pekerjaan yang benar ditunjukkan pada Gambar 2 .

Selanjutnya, jawablah pertanyaan yang berkaitan dengan jawaban masing-masing!

(a) Joko memodelkan masalah di atas dengan benar. Berikut adalah pemodelan yang dilakukan oleh Joko.

Diketahui : $P(0)=100.000$

Ditanyakan : $P(7)$

Model matematika :

$$
\frac{d P}{d t}=0.02 P
$$

Pertanyaan:

i. Mengapa Joko menuliskan $P(0)=100.000$ ?

i. Mengapa Joko berasumsi bahwa yang ditanyakan adalah $P(7)$ ?

iii. Dalam model matematika yang dibuat Joko, terdapat suku $\frac{d P}{d t}$. Mengapa Joko menggunakan suku tersebut bukan $\frac{d t}{d P}$ ?

Gambar 2 Soal yang memuat contoh pekerjaan benar

Tujuan dibuatnya jenis contoh soal yang memuat pekerjaan salah adalah meminta mahasiswa untuk mengetahui letak kesalahan, serta memberikan alasan mengapa hal tersebut salah, dan kemudian memberikan jawaban yang benar. Menggunakan cara ini, mahasiswa menjadi berpikir beberapa kali dalam mengerjakan soal. Selain itu, karena dituntut untuk memberikan justifikasi kesalahan/kebenaran jawaban, mahasiswa menjadi terlatih dalam menyebutkan aturan-aturan yang digunakan dan notasi-notasi yang diperlukan. Contoh soal yang memuat pekerjaan yang salah ditunjukkan pada Gambar 3. Banyak soal yang memuat pekerjaan salah yang disusun ada 10 butir dengan setiap soal memuat beberapa sub soal. Pada penelitian ini, rancangan tugas dibuat untuk untuk dua materi yaitu materi Solusi Persamaan Diferensial dan Pemodelan Persamaan Diferensial. 
(c) Pekerjaan Jessica salah ketika mengerjakan soal poin c. Berikut pekerjaan Jessica:

$$
\begin{aligned}
y\left(\frac{\pi}{3}\right) & =\frac{3}{2} \\
\frac{\pi}{3} \sin (2 t) & =\frac{3}{2} \\
\sin (2 t) & =\frac{9}{2 \pi} \\
\sin (2 t) & =1.4324 \\
t & =\ldots .
\end{aligned}
$$

i. Di bagian manakah Jessica melakukan kesalahan?

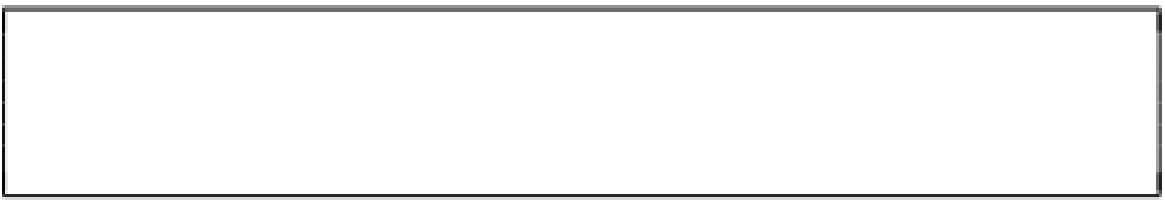

ii. Seharusnya Jessica langsung mengetahui bahwa jawabannya salah, karena ada satu kalimat yang tidak mungkin bernilai benar di jawaban Jessica. Kalimat yang manakah itu? Mengapa kalimat itu tidak mungkin bernilai benar?

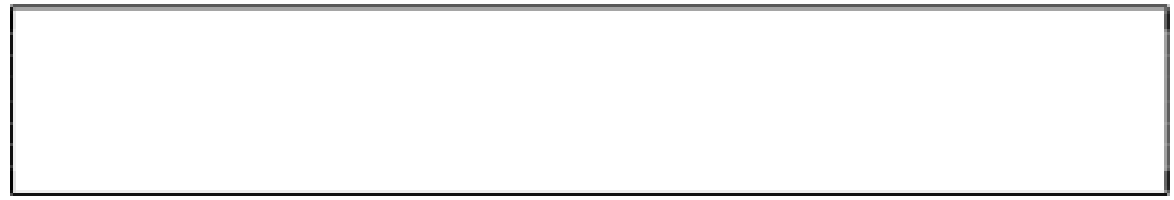

iii. Kerjakanlah soal poin c dengan benar dan tentukan solusi khusus persamaan di atas!

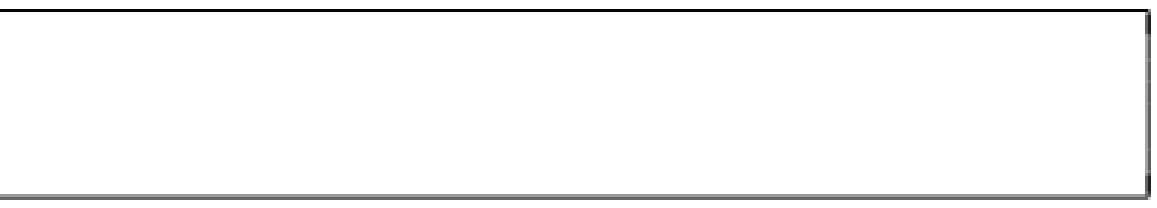

Gambar 3 Soal yang memuat contoh pekerjaan yang salah

\subsection{Respon Mahasiswa}

Setelah mahasiswa diberikan waktu 2 minggu untuk mengerjakan tugas yang memuat contoh jawaban yang keliru, selanjutnya dipilih 2 orang mahasiswa untuk diwawancarai. Kedua orang mahasiswa tersebut merupakan mahasiswa yang memiliki tingkat motivasi yang cukup besar dalam mengikuti pembelajaran. Dipilihnya mahasiswa yang demikian karena mahasiswa yang memiliki motivasi tinggi cenderung serius dalam mengerjakan tugas yang "tidak biasa", sehingga pendapat mereka sangat berharga. Untuk mahasiswa yang tergolong enggan mengerjakan tugas, respon mereka dapat terlihat pada lembar jawaban yang sebagian besar kosong. Sedangkan pendapat mereka mengenai tugas tersebut dapat diketahui dengan cara menanyai secara klasikal. Hal ini disebabkan peneliti tidak ingin mahasiswa merasa dihakimi dengan pertanyaan yang diberikan.

Hasil wawancara dengan Responden 1, menunjukkan bahwa tugas dengan metode contoh yang keliru memberikan tantangan yang lebih dalam pengerjaannya. Hal ini ditunjukkan dengan kalimat

“... mengerjakan tugas Ibu itu memerlukan waktu yang tidak sedikit. Seringkali sehari hanya dapat satu soal saja. Karena berkali-kali harus melihat buku Kalkulus lagi. Apa benar cara menurunkannya seperti ini, apa benar seperti itu. Jadi harus berkali-kali mengecek fakta."

Ketika Responden 1 diminta untuk menentukan lebih sulit mana menjawab soal dengan kesalahan atau menjustifikasi jawaban benar, Responden 1 menjawab 
"Kalau menurut saya, lebih sulit mejawab pertanyaan yang memuat jawaban yang benar. Karena untuk jawaban yang sudah benar, kita diminta untuk memberikan alasan mengenai langkah-langkah pengerjaannya. Seperti Soal No. 1 a, soal tersebut membuat kita harus bisa berkata-kata mengapa menulis itu. Hal ini sebenarnya tidak sulit, tetapi kalau tidak terbiasa berargumen ya jadi sulit."

Sedangkan untuk soal yang memuat kesalahan, Responden 1 merasa bahwa soal tidak terlalu sulit terutama dalam menentukan letak kesalahan. Yang dinilai lebih sulit adalah jika pertanyaannya meminta responden untuk memberikan alasan.

“... yang sulit adalah kalau kita diminta untuk memberi alasan mengenai jawaban salah. Biasanya kita tahu kesalahannya tetapi alasannya kan karena memang itu salah. Gimana ya mengungkapkannya?"

Setelah diklarifikasi ulang, ternyata responden merasa bahwa letak kesalahan tidak terlalu sulit untuk diketahui. Akan tetapi ketika mereka diminta untuk memberikan alasan mengapa jawaban tersebut salah, mereka kesulitan. Hal ini diketahui dari hasil triangulasi data yang menunjukkan bahwa sebagian dari mereka memberikan alasan

"Jawaban salah, karena yang benar adalah ...."

Hal ini menunjukkan bahwa mahasiswa masih kesulitan dalam menjelaskan pendapat mereka dengan bahasa mereka sendiri. Mereka kesulitan dalam menentukan istilah yang harus dipakai dan menyusunnya dalam kalimat. Sebagai contoh, ketika letak kesalahan pengerjaan adalah salah dalam mengaplikasikan Aturan Rantai, dari jawaban satu kelas tersebut, tidak ditemukan satu pun mahasiswa yang menggunakan istilah Aturan Rantai. Akan tetapi mereka langsung mendemonstrasikan Aturan Rantai tersebut dalam mengerjakan soal.

Adapun Responden 2 berpendapat bahwa tugas dengan model seperti itu membuat mahasiswa tidak bisa sembarang menjawab tugas. Mahasiswa mau tidak mau harus berusaha memahami contoh jawaban yang diberikan dan mengecek fakta dengan membaca buku-buku Kalkulus Diferensial. Selain itu, mahasiswa juga dipaksa untuk berdiskusi ketika diminta untuk memberikan alasan. Hal ini dipertegas dengan kalimat

"Ketika mengerjakan tugas tersebut, banyak versi alasan yang muncul dari temanteman yang lain. Akibatnya, ketika diskusi malah jadi bingung. Meskipun akhirnya diklarifikasi oleh Ibu, tetapi pas mengerjakan itu jawaban tiap orang bisa beda-beda.”

Hal ini menunjukkan bahwa tugas dengan model soal tersebut memberikan pengalaman diskusi untuk mahasiswa yang mungkin tidak diperoleh mereka dari tugas yang biasanya. Ini merupakan nilai positif dari metode contoh yang keliru. Selain itu, biasanya mahasiswa mengikuti contoh soal untuk mengerjakan suatu masalah. Akan tetapi, dengan metode contoh yang keliru, mahasiswa dituntut tidak hanya melihat dan mengikuti contoh soal, tetapi juga menganalisis kebenaran langkah per langkah. Hal ini benar-benar membuat mahasiswa berpikir dan belajar.

Temuan penting lainnya adalah model tugas tersebut juga dapat membuat beberapa siswa berbeda pendapat sehingga terjadi adu argumen di antara mereka. Adu argumen yang terjadi biasanya karena mereka memiliki pendapat yang berbeda dalam menjustifikasi alasan mengapa contoh jawaban yang diberikan di soal salah. Hal ini merupakan hasil yang sangat positif karena tujuan penelitian ini adalah untuk mengembangkan suatu paket pembelajaran yang dapat digunakan untuk melatih kemampuan komunikasi matematis mahasiswa. Menurut NCTM, kemampuan komunikasi matematis dapat dilatih jika mahasiswa secara konsisten sering mengalami adu argumen dan menemui soal yang menantang kemampuan komunikasi mereka (Lange et al., 2014). Dengan demikian, dapat disimpulkan bahwa metode contoh yang keliru sesuai untuk melatih kemampuan komunikasi matematis mahasiswa.

\section{Simpulan}

Berdasarkan hasil uraian di atas, dapat disimpulkan bahwa metode contoh yang keliru dapat digunakan dalam pembelajaran matematika terutama dalam hal pemberian variasi dalam tugas. Tugas dengan metode ini dapat melatih siswa dalam memeriksa fakta, berargumen, dan mengungkapkan pendapat. 
Adapun saran yang dapat diberikan adalah bahwa penelitian ini baru mencoba penerapan metode contoh yang keliru pada materi yang memuat langkah-langkah prosedural. Sepanjang pegetahuan peneliti, metode ini belum pernah dicoba untuk materi matematika yang menuntut mahasiswa menyelesaikan masalah kontekstual.

\section{Acknowledgment}

Penelitian ini merupakan bagian dari Penelitian Dosen Pemula yang berjudul "Pengembangan Program Blended Learning Berbasis Erroneous Example (Contoh Yang Keliru) Untuk Meningkatkan Kemampuan Komunikasi Matematis Mahasiswa “ yang dibiayai oleh DRPM DIKTI Tahun 2018. Untuk itu, tim peneliti mengucapkan rasa terima kasih yang sebesar-besarnya atas kesempatan ini. Semoga artikel ini dan penelitian tersebut bermanfaat bagi pengembangan ilmu pendidikan matematika di Indonesia.

\section{Referensi}

Abdullah, A. H., Abidin, N. L. Z., \& Ali, M. (2015). Analysis of students' errors in solving Higher Order Thinking Skills (HOTS) problems for the topic of fraction. Asian Social Science, 11(21), 133-142. https://doi.org/10.5539/ass.v11n21p133

Ang, L. H., \& Shahrill, M. (2014). Identifying Students' Specific Misconceptions in Learning Probability. International Journal of Probability and Statistics, 3(2), 23-29. https://doi.org/10.5923/j.ijps.20140302.01

Jaeger, A. J., Marzano, J. A., \& Shipley, T. F. (2020). When seeing what's wrong makes you right: The effect of erroneous examples on 3D diagram learning. Applied Cognitive Psychology, 34(4), 844-861. https://doi.org/10.1002/acp.3671

Kay, R., \& Edwards, J. (2012). Examining the Use of Worked Example Video Podcasts in Middle School Mathematics Classrooms: A Formative Analysis. Canadian Journal of Learning and Technology, 38(2).

Lange, K. E., Booth, J. L., \& Newton, K. J. (2014). Learning Algebra from Worked Examples: Presenting examples of both correctly and incorrectly worked solutions is a practical classroom strategy that helps students counter misconceptions about algebra. Mathematics Teacher, 107(7), 534-540. www.nctm.org.

McGinn, K. M., Lange, K. E., \& Booth, J. L. (2015). A Worked Example for Creating Worked Examples. Mathematics Teaching in the Middle School, 21(1), 26-33. https://doi.org/10.5951/mathteacmiddscho.21.1.0026

McLaren, B. M., Van Gog, T., Ganoe, C., Karabinos, M., \& Yaron, D. (2016). The efficiency of worked examples compared to erroneous examples, tutored problem solving, and problem solving in computer-based learning environments. Computers in Human Behavior, 55, 87-99. https://doi.org/10.1016/j.chb.2015.08.038

Mctavish, T. S., \& Larusson, J. A. (2014). Discovering and Describing Types of Mathematical Errors. Proceedings of the 7th International Conference on Educational Data Mining (EDM), 353-354.

Melis, E. (2004). Erroneous Examples as a Source of Learning in Mathematics. International Association for Development of the Information Society Conference for Cognition Exploratory Learning in Digital Age (CELDA), 311-318. https://pdfs.semanticscholar.org/17be/73f009cf0df2a4523f099fbf0db42180679a.pdf

Melis, E. (2005). Design of Erroneous Examples for ActiveMath. Proceedings of the 12th International Conference on Artificial Intelligence in Education, 451-458.

Nasution, N. B. (2018). Analisis Kesalahan Mahasiswa Pada Materi Fungsi Dua Peubah Dengan Newmann'S Error Analysis (Nea). Delta: Jurnal Ilmiah Pendidikan Matematika, 6(1), 21. https://doi.org/10.31941/delta.v6i1.730 
Nasution, N. B., \& Mardhiyana, D. (2019). Implementasi Moodle dengan Metode Erroneous Example (Contoh yang Keliru) pada Pembelajaran Kalkulus Lanjut. PRISMA, Prosiding Seminar Nasional Matematika, 2, 597-605.

Tsovaltzi, D., Melis, E., McLaren, B. M., Dietrich, M., Goguadze, G., \& Meyer, A. K. (2009). Erroneous examples: A preliminary investigation into learning benefits. Lecture Notes in Computer Science (Including Subseries Lecture Notes in Artificial Intelligence and Lecture Notes in Bioinformatics), 5794 LNCS(October 2009), 688-693. https://doi.org/10.1007/978-3642-04636-0_69

Tsovaltzi, D., Melis, E., McLaren, B. M., Meyer, A. K., Dietrich, M., \& Goguadze, G. (2010). Learning from erroneous examples: When and how do students benefit from them? Lecture Notes in Computer Science (Including Subseries Lecture Notes in Artificial Intelligence and Lecture Notes in Bioinformatics), 6383 LNCS, 357-373. https://doi.org/10.1007/978-3-64216020-2_24

van Loon-Hillen, N., van Gog, T., \& Brand-Gruwel, S. (2012). Effects of worked examples in a primary school mathematics curriculum. Interactive Learning Environments, 20(1), 89-99. https://doi.org/10.1080/10494821003755510

Yee Ming, C., Pei Eng, ng, Set Foong, N., Kok Shien, N., \& Teknologi MARA Cawangan Pulau Pinang, U. (n.d.). Undergraduates' Error Patterns And Misconceptions In Further Differential Equations. International Academic Research Journal of Social Science, 3(1). Retrieved August 16, 2017, from http://www.iarjournal.com/wp-content/uploads/IARJSS2017_1_65-70.pdf 